\title{
GESAMTSYSTEM IM FOKUS
}

\section{FOCUS ON THE COMPLETE SYSTEM}

Dear Reader,

Technology development for mobile machines is currently being driven by efficient, low-emission powertrain concepts that conserve resources. However, the focus of development must be shifted once again towards system optimisation. For example, improving the diesel engine alone is a step in the wrong direction, due to strict emissions legislation and the testing regulations currently in force. Improving one component, such as the transmission, will not achieve such good results as the consideration and optimisation of the system as a whole.

Compared to developers of passenger car transmissions, those developing mobile construction and agricultural machines have to meet tougher requirements, considering the fact that the car industry builds between 200 and 300 prototypes for one model series. This amount of effort is not possible in the off-highway sector, as series production volumes are much smaller. For that reason, development programmes have to be significantly tightened with regard to time and, in particular, with regard to the amount of effort involved. "In doing so, we are taking somewhat greater risks," says Hermann Beck from ZF Friedrichshafen, for example, in our interview on page 33 .

What is more, the different requirements of the worldwide markets represent major challenges for manufacturers. For example, the technology levels required in China or India are completely different from those in the USA or Germany. A clear overview of precisely which transmission concepts are used for tractors in the various markets is given by Professor Renius in his article on page 18. Making this variety of transmissions available cost-effectively requires market-driven products which have to be produced at the various sites concerned. The greatest challenge facing manufacturers is to generate synergies between the different technology levels, for example by applying platform approaches.

I hope you enjoy reading our informative articles.

Best regards, 